\title{
The impact of Big Data on the Android Mobile Platform for Natural Disaster Situations
}

\author{
Zijadin Krasniqi ${ }^{*}{ }^{1}$, Adriana Gjonaj ${ }^{2}$ \\ ${ }^{1}$ Department of Information Technology, Tax Administration of Kosovo. \\ ${ }^{2}$ Department of Informatics, Mathematics, and Statistics, European University of Tirana, Albania.
}

\begin{tabular}{l} 
A R T I C L E I N F O \\
\hline Article history: \\
Received: 10 January, 2018 \\
Accepted: 06 March ,2018 \\
Online: 31 March ,2018 \\
\hline Keywords: \\
Android \\
OCEMA \\
Big Data \\
DWH \\
Natural Disasters \\
\end{tabular}

\begin{abstract}
A B S T R A C T
This application developing for the project OCEMA comes as result of architecture building in Android, then the development of a professional modeling in Talend Open Studio for Big Data, which enabled the integration of data from many data sources. One of its uses is the quick identification of people found in areas affected by natural disasters. The application identifies the persons who do not have an ID card, or another identification document, by using identification through fingerprint or personal number. OCEMA Application has access to all the agencies involved in natural disasters managing, such as ISK, HMIK, MIK, FSK and CRA. This application is developed to connect to web applications as well, such as applications, which gather real time information on earthquakes and weather in the world.

The study of literature and the actual work with these systems has shown some important components of success for DWH systems, DataMart and mobile application development.
\end{abstract}

\section{Introduction}

In the year 2002 alone, disasters affected a staggering 680 million people worldwide. Natural disasters include bring earthquakes, flooding, droughts, heat waves, cold spells and events that destroy countries, businesses and individual property and well-being. The goal of this study is to investigate the adoption of cell phones as preparedness efforts during the natural disaster seasons in a developing country. Since Kosovo is a country vulnerable to natural disasters, the present study aims to investigate the adoption of cell phones for natural disaster preparedness [1]

OCEMA applications initially are secured by a username and password, and then divided in 5 buttons, such as: ISK, CRA, HMIK, MIK and FSK. This application enables access to real time information, such as in the case of the agency of civil register, offering two possibilities to identify the victims of natural disasters.

It uses the identification through personal number, but in cases where there is no ID card, the identification can be done using the fingerprints. Part of this application is access to institutions such as the Institution of Seismology, the Medical Institution, the Hydro meteorological Institution and the Firefighter's Service.

*Zijadin Krasniqi, Tax Administration of Kosovo, zijadinkrasniqi@hotmail.com
These institutions have updated information. Beside this, the OCEMA application has the possibility to access important web pages in order to monitor climate and seismic conditions in world level.

\section{Mobile Platforms}

The four most common smart phone operating systems, by market share in the third quarter of 2013 (IDC 2013) are:

-Android by Google, with a distinct dominance at $81 \%$, -iOS, on Apple's iPhone, at $12.9 \%$,

-Windows Phone by Microsoft at 3.6\%

-and BlackBerry at $1.7 \%$.

There are many significant differences between these platforms. Some are visible to the users such as availability of specific features or design of the user interface (UI), and some are invisible to the users but affect the developers of mobile applications.

\subsection{Android architecture}

Starting from the bottom we have Linux Kernel, Android is built up on the Linux Kernel. Linux is already being used extensively from so many years and its kernel had received so many security patches. Linux Kernel provides basic system functionality like 
process management, memory management, device management like camera, keypad, display etc.

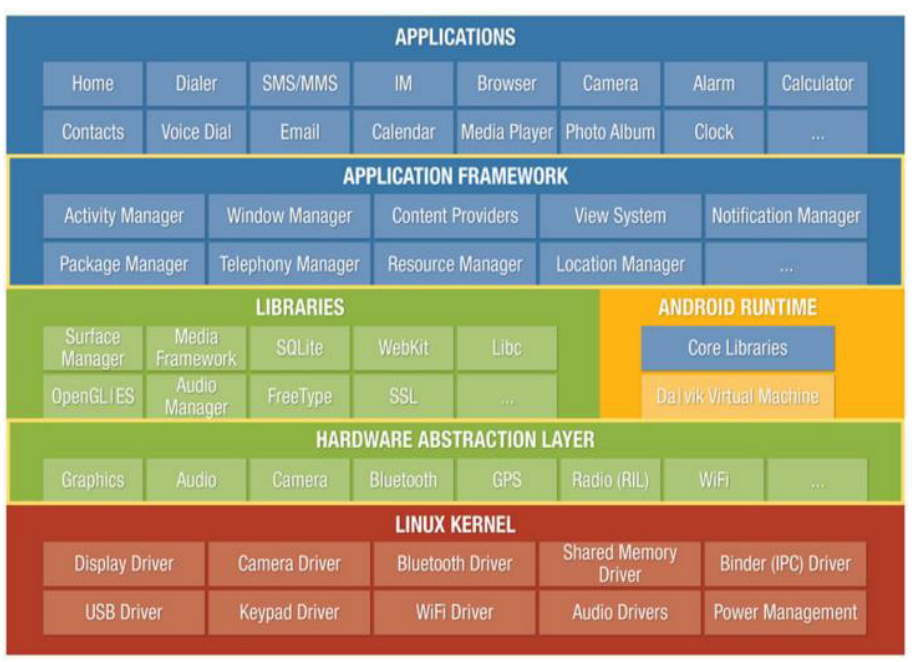

Figure 1: Android Architecture [2]

As the base for a mobile computing environment, the Linux kernel provides Android with several key security features, including:

- A user-based permissions model

- Process isolation

- Extensible mechanism for secure IPC

- The ability to remove unnecessary and potentially insecure parts of the kernel.

As a multiuser operating system, a fundamental security objective of the Linux kernel is to isolate user resources from one another. The Linux security philosophy is to protect user resources from one another [2]

Taking into consideration the Android as a target platform for application comes as the result of reviewing various works using Android technology.

The Android SDK allows application development with great ease. There are many inbuilt features and tools in an Android device, which can be integrated and programmed to be used as and when required from within the application [3]

\section{Case study: SQLite_OCEMA database integration can be implemented in Android mobile devices}

The operational Centre of the Emergency Management Agency requires analysis in daily, weekly and monthly bases. What is most important is the capability of real time data analysis. Therefore, this increases the need for data collection and data integration in a single database. The scope is to be able to analyze possible problems faced during emergency situations and natural hazards and then determine the highest levels of entities from which we can collect data.

The following data form the bases of the conceptual model of OCEMA database, which we are going to build.

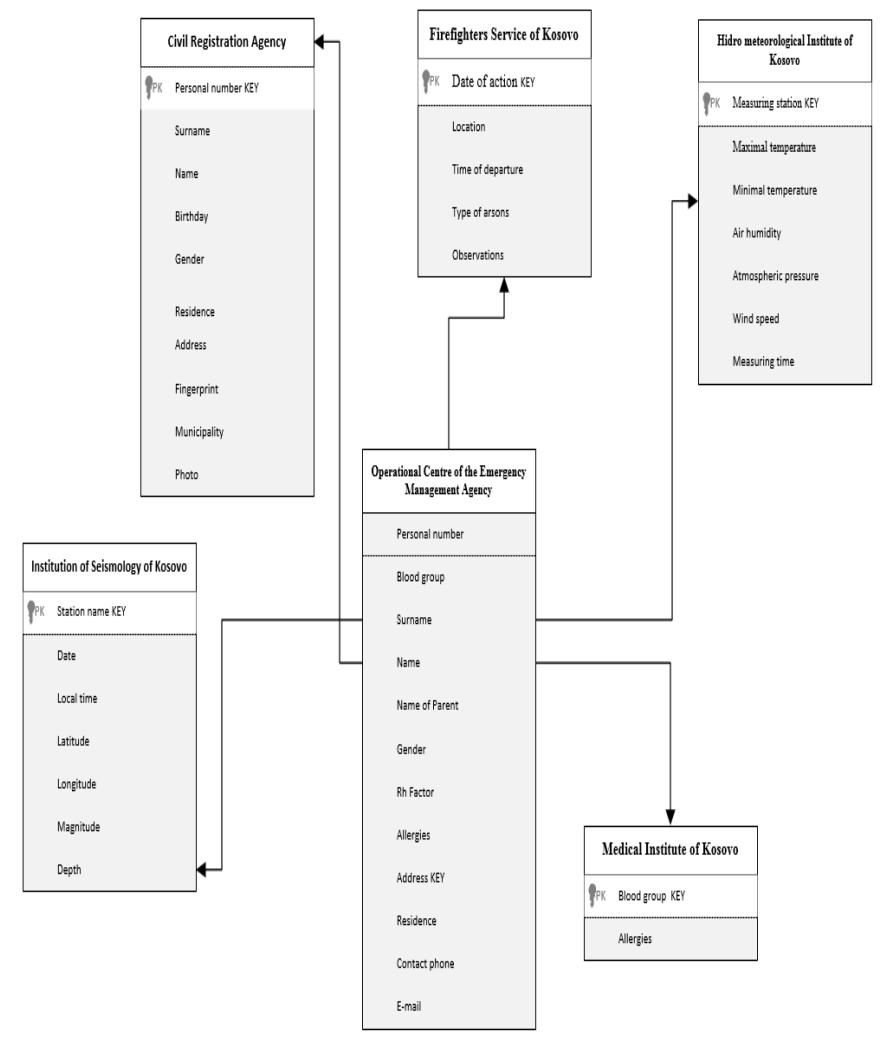

Figure 2: The Entity Relationship diagram of OCEMA database

We start with the description of the entities used in the OCEMA database.

The entity named Medical Institute of Kosovo is composed of the following data: Blood group for the patients and the eventual allergies present in the population. Entry data from MIK are an important information source at national level as far as the health of the population is concerned.

The entity named Civil Registry Agency includes several fields involving records on entry data regarding the civil registration at a national level, among them including the following characteristics: personal number, surname, name, date of birth, residence, address, fingerprints, district and photo.

All these attributes of the CRA entity include the population's records. In our study, the principal searching attributes on individuals will be the personal number and the fingerprints.

The entity named Institute of Seismology of Kosovo includes the following attributes: name of the weather station from where we get the real time data on seismic waves and information from the instruments of online monitoring of seismic waves.

Then in this entity we include: the date of seismic waves, local time, latitude, longitude, magnitude and seismic depth.

The data entity generated by the Hydro meteorological Institute of Kosovo includes a very significant dynamics of available data aiming the comprehensive real time monitoring in order to prevent flooding from rainfall, snow and also extreme draught caused by extreme maximal temperatures. 
This entity includes the following attributes: the weather measuring station, maximal temperature, minimal temperature, air humidity, atmospheric pressure, wind speed, measuring time. It is very important to keep under control the continuous monitoring and observation of many factors, which affect arsons, such as the case of arsons involving homes, forests and pastures.

The entity of Firefighters Service is composed of the following attributes: date of action, location, time of departure, type of arsons, observations. All of these offer a very good opportunity to get information from this very important institution.

\section{Data integration in SQLite_OCEMA through Talend Open Studio for Big Data}

We have chosen SQLite as the main database, where we will integrate the tables from Oracle SQL, such as: CRA, HMIK, MIK, ISK and FSK. Most of the enterprise companies use Oracle in their applications in order to load data. In the case of data loading in SQLite_OCEMA, we have built the following job in Talend Open Studio for Big Data, as shown in the Figure below:

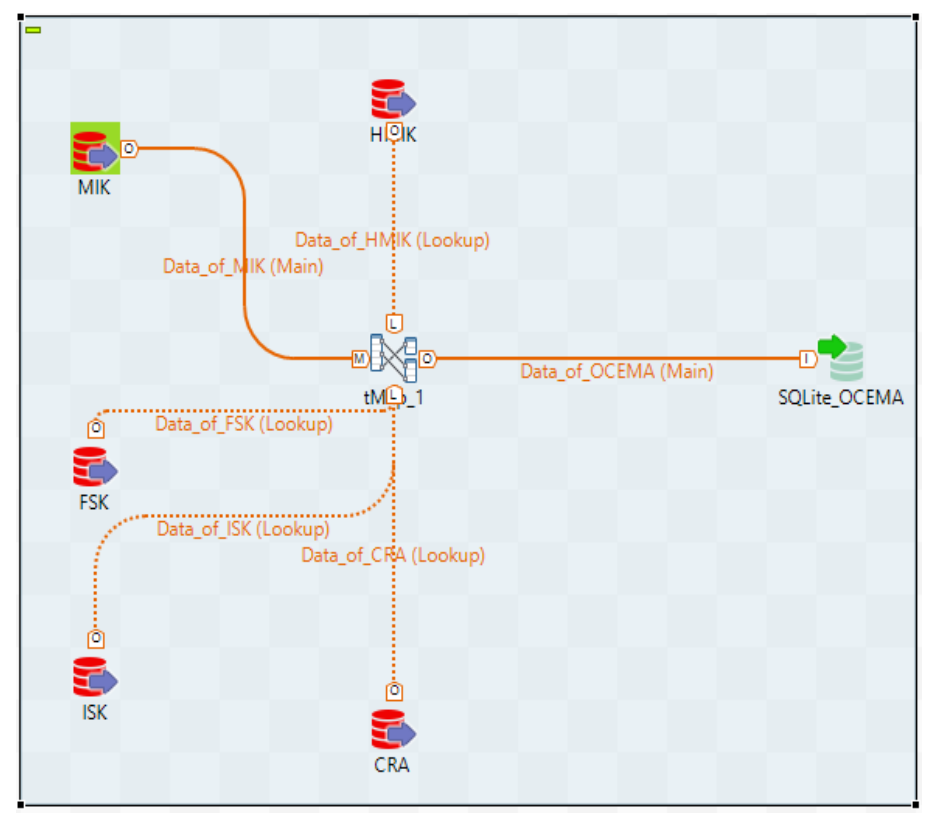

Figure 3: Talend's Job for data loading from the ORACLE SQL tables in SQLite_OCEMA

These heterogeneous data sources, HMIK, MIK, FSK, ISK and CRA, then will be stored in SQLite_OCEMA databases, as shown in the TOS schema.

An important step in ensuring the job developing with ETL is the successful connection between TOS and SQLite_OCEMA database.

\subsection{Projecting the SQLite_OCEMA database}

Unlike most RDBMS products, SQLite does not have client/server architecture. Most large-scale database systems have a large server package that makes up the database engine.

The database server often consists of multiple processes that work in concert to manage client connection, I/O files, caches, query optimization and query processing. A database instance typically consists of a large number of files organized into one or more directory trees on the server's file system.

In order to access the database, all the files must be present and correct. This can make it somewhat difficult to move or reliably back up a database instance. To access the database, client software libraries are typically provided by the database vendor. These libraries must be integrated into any client application that wishes to access the database server.

These client libraries provide APIs to find and connect to the database server, as well as set up and execute database queries and commands. The Figure 4 below shows how everything fits together in a typical client/server RDBMS.

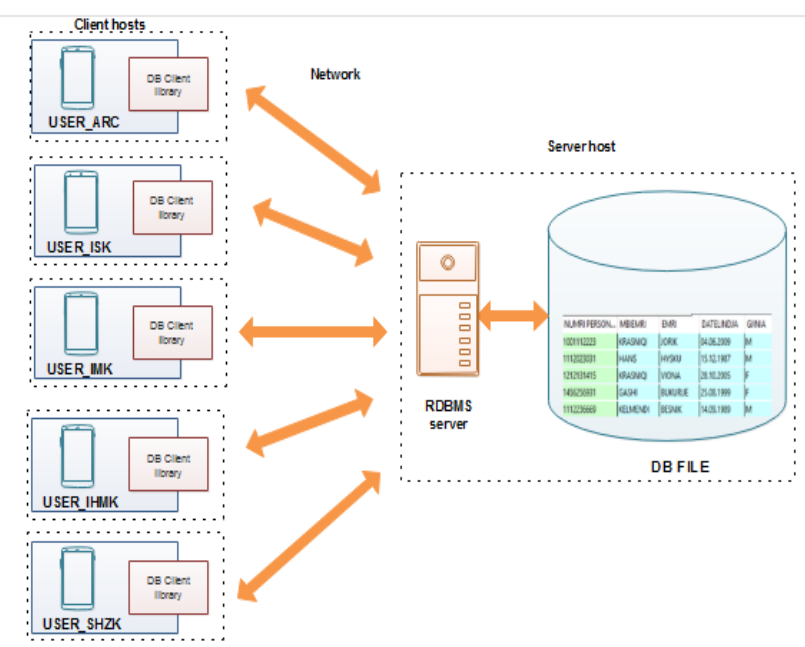

Figure 4: Client/server RDBMS architecture [4]

In contrast, SQLite does not have a separate server. The entire database engine is integrated into whatever application needs to access a database.

The only shared resource among applications is the single database file as it sits on disk. If we need to move or back up the database, we can simply copy the file. Below, in the Figure 5, we will see the SQLite architecture.

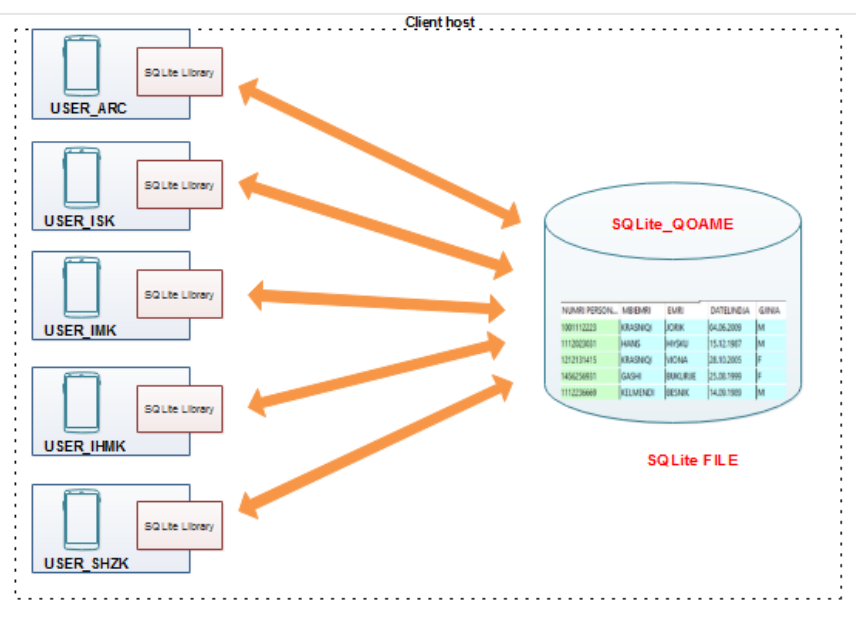

Figure 5: The SQLite server architecture [4] 
By eliminating the server, a significant amount of complexity is removed. This simplifies the software components and nearly eliminates the need for advanced operating support. Unlike a traditional RDBMS server that requires advanced multitasking and high performance inter-process communication, SQLite requires little more than the ability to read and write to some type of storage.SQLite is designed to be integrated directly into an executable. This eliminated the need for an external library and simplifies distribution and installation. Removing external dependencies also removes most versioning issues.

If the SQLite code is built right into the application, we never need to worry about linking to the correct version of a client library or that the client library is version-compatible with the database server. Eliminating the server imposes some restrictions. SQLite is designed to address localize storage needs, such as a web server accessing the local database. This means it isn't well suited for situations where multiple client machines need to access a centralized database. That situation is more representative of client/server architecture and is better serviced by a database system that uses the same architecture. [4]

\subsection{SQLite_OCEMA database-the case of android application for CRA}

Android uses the SQLite database system, which is an opensource, stand-alone SQL database, widely used by many popular applications.

SQLite is a lightweight transactional database engine that occupies a small amount of disk storage and memory, thus, it is a perfect choice for creating databases on many mobile operating systems such as Android and iOS [2]

The Android platform offers full support for SQLite databases. The created database will be accessible by name from each of the classes inside the application, not those from outside. In our case, when we are searching the data from the Civil Registration Agency in case of emergencies and natural disasters, we have the possibility to search for missing people during lifesaving operations and also in the warning period of natural hazards.

Thus, we use the personal number identification method to find people struck there where the natural disaster happened. If we take the Civil Registration Agency table of the SQLite_OCEMA database as in the following Table 1:

Table 1: Civil Registration Agency data table in the SQLite_OCEMA database.

\begin{tabular}{|c|l|l|l|l|l|l|}
\hline Personal number & Surname & Name & Birthday & Gender & Municipality & \multicolumn{1}{|c|}{ Address } \\
\hline \hline 1001112223 & KRASNIQI & JORIK & 04.06 .2009 & M & PRISHTINE & "Bajram Bahtiri" \\
\hline 1112023031 & HANS & HYSKU & 15.12 .1987 & M & PEIE & "Lidhja e Prizrenit" \\
\hline 1212131415 & KRASNIQI & VIONA & 28.10 .2005 & F & PODUJEVE & "Ismail Dumoshi" \\
\hline 1456256931 & GASHI & BUKURIJE & 25.08 .1999 & F & MITROVICE & "Bajram Bahtiri" \\
\hline 1112236669 & KELMENDI & BESNIK & 14.09 .1989 & M & FERIZAI & "Lidhja e Prizrenit" \\
\hline 1488523691 & HALILI & LUM & 25.03 .2011 & M & PRIZREN & "Bajram Bahtiri" \\
\hline 2581473691 & KADRIU & LIRI & 18.02 .2000 & F & PEIE & "Bajram Bahtiri" \\
\hline 3698521471 & GASHI & ISA & 23.04 .1988 & M & PEJE & "Lidhja e Prizrenit" \\
\hline 1234567893 & KODRA & GEZIM & 01.01 .1975 & M & PRISHTINE & "Ismail Dumoshi" \\
\hline 1593574562 & TELAKU & TRIM & 02.02 .2012 & M & DEÇAN & "Bajram Bahtiri" \\
\hline 1235661114 & RUGOVA & JORIK & 14.09 .2014 & M & PRISHTINE & "Lidhja e Prizrenit" \\
\hline 4569871233 & HALILI & RRON & 14.05 .2007 & M & PEJE & "Ismail Dumoshi" \\
\hline 1488523691 & HALILI & LUM & 25.03 .2011 & M & PRIZREN & "Bajram Bahtiri" \\
\hline
\end{tabular}

\section{Searching the SQLite_OCEMA data using the personal number}

If we set as criteria the searching of data using the personal number method from the SQLite_OCEMA database and we use the recommended methods to create a new SQLite database.

When a database has been successfully opened, the SQLite Open Helper will cache it, so you can (and should) use these methods each time you query or perform a transaction on the database, rather than caching the open database within your application.

A call to getWritableDatabase can fail due to disk space or permission issues, so it's good practice to fall back to getReadableDatabase method for database queries if necessary. In most cases this method will provide the same, cached writeable database instance as getWritableDatabase [5]. An example is shown in the Figure 6.

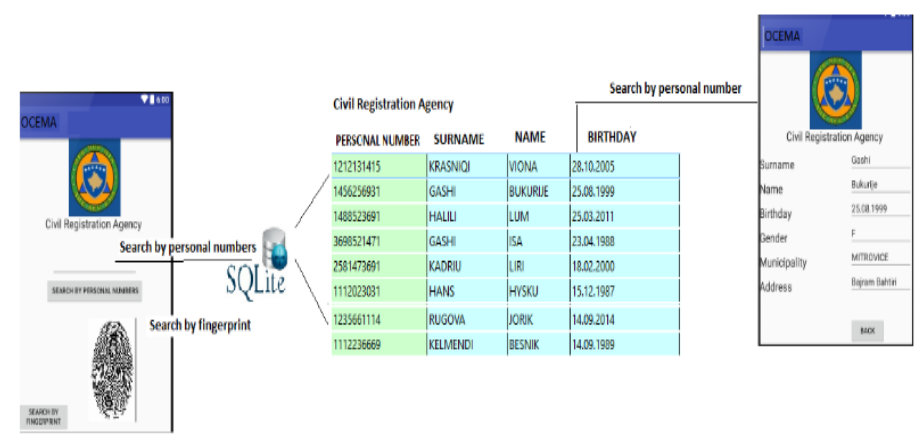

Figure 6: Searching by personal number in SQLite_OCEMA database [6]

This is a part of the application development. In this part, we search for people struck by natural disasters and emergency situations by using the fingerprint method, as shown in the Figure.

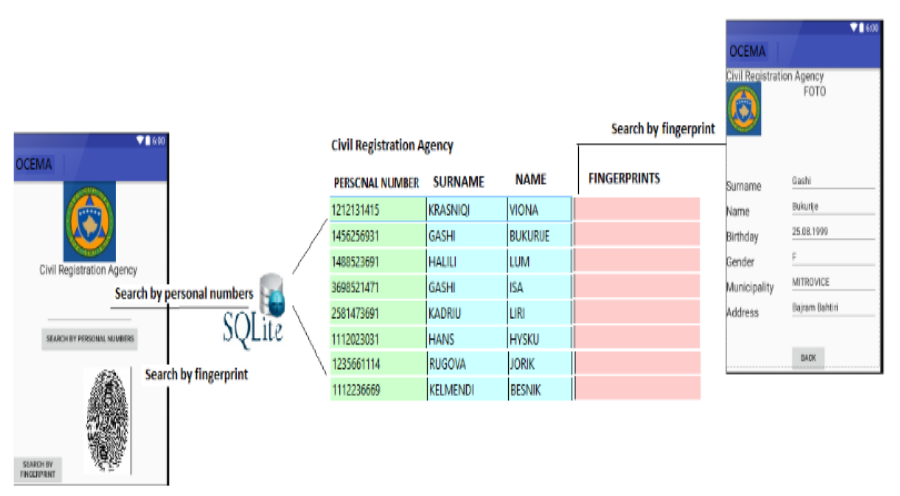

Figure 7: Searching by using the fingerprints in SQLite_OCEMA database.[6]

This result is displayed every time the user launches the matching activity from our proposed application, by comparing the initial fingerprint with the ones stored in database.

One utility of the proposed application consists in quick identification of the people struck in areas hit by natural hazards or emergency operations, in the quick identification of those people who do not have an ID card or another document of identification, by using the fingerprints identification method. 
Also, the application could be deployed in the access systems of the public institutions like schools, libraries, hospitals and so on[7]

\section{SQLite_OCEMA database- the case of android application for ISK}

The Institution of Seismology has a large number of weather measuring stations across the territory of Kosovo. These stations transmit their data to the institute on daily, weekly and monthly bases. Upon creating and building the SQLite_OCEMA database, these data can be reported in a shorter time, better to say in real time across all the weather measuring stations.

By clicking on the ISK (Institute of Seismology of Kosovo) button in the OCEMA basic application, we gain access to search the latest updated ISK data, as shown below in the Figure 8.

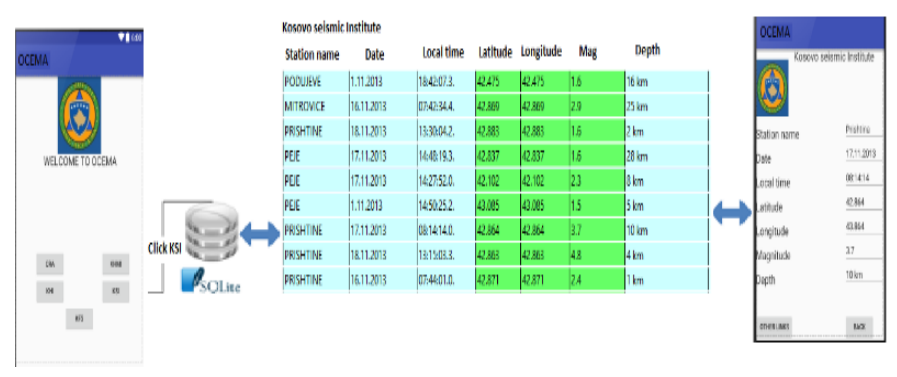

Figure 8: Access to the data of Institute of Seismology of Kosovo. [6]

After the creation of the Institution of Seismology of Kosovo table in the SQLite_OCEMA database, we can click on the ISK button to search the latest updated data of this institution, including magnitude of seismic waves, seismic depth, geographical position, latitude-longitude, date and time of the seismic wave.

\section{SQLite_OCEMA database, the case of Android application for HMIK}

The Hydro meteorological Institute of Kosovo has a large number of weather measuring stations across the territory of Kosovo. These stations transmit their data to the institute on daily, weekly and monthly bases. Upon creating and building the SQLite_OCEMA database, these data can be reported in a shorter time, better to say in real time across all the stations, including data from the river flows, data from sensors placed in locations where there is more snow.

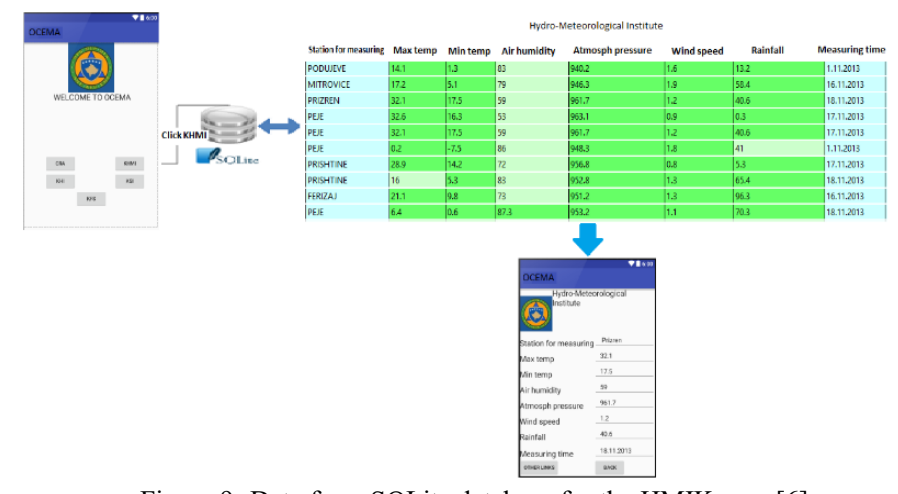

Figure 9: Data from SQLite database for the HMIK case [6]
Thanks to this application we have been able to get detailed information from all the weather measuring stations in the territory of Kosovo, which provide a representation of warnings in case of flooding from atmospheric precipitations, wind speed, air humidity and the maximum and minimum temperatures.

\section{Conclusion}

Mobile technology has shown a considerable impact on society over the past few years. Gradually, this technology has become part of every person's life and is the easiest mode to deliver information. The development of application OCEMA for the doctoral project comes as a result of building architecture in Android Platform, then a professional model in Talend Open Studio for Big Data, which enabled the data integration from multiple data sources. Then we have developed the applications in Android Platform using the Java programming language. We have made it possible to reach near real time representation of the sources.

It is widely known that during natural disasters and emergencies, we do not have all the information available, but in those moments, everything is important, above all the information related to the human factor. EMA should be aware of these kinds of situations and precede the capacity building in systems communication and developing applications for the management of emergencies and natural disasters.

\section{References}

[1] A. Lawson, L.Willoughby, "Adoption of cell phones as preparedness efforts for natural disasters", Issues in Information Systems, International Association for Computer Information Systems, USA, 2012, Vol. 13, pp 11$20 \mathrm{http}: / /$ iacis.org/iis/2012/79_iis_2012_11-20.pdf

[2] A.Agrawal "Android Application Security Part 2-Understanding Android Operating System", 2015, http://manifestsecurity.com/android-applicationsecurity-part-2

[3] T. Tejassvi, "An Android application to support flash flood disaster response management in India" M.sc Thesis, University of Twente -Netherlands, 2014.

[4] J. Kreibich, Using SQLite, Published by O'Reilly Media, 2010, USA.

[5] R. Meier, Professional Android 4 Application Development, John Wiley \& Sons, Inc., 2012, Canada.

[6] EMERGENCY MANAGEMENT AGENCY-LOGO https://ame.rks-gov.net/en/Home/PgrID/494/PageID/4.

[7] O.Dospinescu,I. Lîsîi ,"The Recognition of Fingerprints on Mobile Applications - an Android Case Study", IBIMA Publishing, Romania,2016 http://ibimapublishing.com/journals/JEERBE/2016/813264/813264.html 